\title{
PROPOSTA DE MODELO PARA AVALIAÇÃO DE TUTORES BASEADO EM FEEDBACK $360^{\circ}$.
}

CANINDÉ/CE JULHO/2018

\author{
Francisco Luciano Castro Martins Júnior ～- IFCE - lucianojrcm@gmail.com
}

Tipo: Investigação Científica (IC)

Natureza: Planejamento de Pesquisa

Categoria: Pesquisa e Avaliação

Setor Educacional: EDUCAÇÃO SUPERIOR, EDUCAÇÃO CONTINUADA EM GERAL

\begin{abstract}
RESUMO
Graças aos avanços tecnológicos, a Educação a Distância conseguiu se popularizar e se firmar como modalidade de ensino, representando hoje uma parcela significativa das matrículas. Nessa modalidade é importante a atuação do tutor nas atividades de mediação entre o aluno e a instituição de ensino no decorrer do processo de aprendizagem. Desse modo, é fundamental que a tutoria seja desempenhada de modo a favorecer os objetivos institucionais e do aluno. Devido a isso é necessário acompanhar o desempenho do tutor em suas funções. O presente trabalho propõe um modelo de avaliação de desempenho de tutores baseado na metodologia de avaliação feedback $360^{\circ}$. O objetivo da pesquisa é desenvolver um modelo de avaliação com caráter qualitativo considerando as atividades e habilidades necessárias à atividade de tutoria. No modelo é proposto um foco múltiplo sobre a atuação do tutor, o qual é avaliado por todos os atores que com ele convivem no processo de ensinoaprendizagem. Para construção do modelo, foi realizada pesquisa bibliográfica no intuito de coletar informações sobre os aspectos da tutoria, metodologias de avaliação de tutores e sobre a metodologia de feedback $360^{\circ}$. Assim, a pesquisa resultou em uma ferramenta de avaliação de cunho qualitativo e que possibilita a participação de todos os envolvidos com o trabalho do tutor, possibilitando uma análise ampla e abrangente. Assim, espera-se que a aplicação da metodologia ora proposta possa contribuir com a identificação de problemas e potencialidades, possibilitando as intervenções eventualmente necessárias e resultando na melhoria na qualidade do trabalho dos tutores e, consequentemente, dos resultados de aprendizagem.
\end{abstract}

Palavras-chave: Avaliação, Tutor, Feedback 360, modelo de avaliação.

\section{AGRADECIMENTOS}

AO IFCE PELO EXPERIÊNCIA NO ENSINO E À UNOPAR PELA FORMAÇÃO NA ÁREA DE EDUCAÇÃO A DISTÂNCIA. 


\section{1 - INTRODUÇÃO}

O cenário em EaD é composto basicamente pelos seguintes agentes: alunos, professores, tutores e gestores/coordenadores. No documento publicado pelo Ministério da Educação e Cultura - MEC, que estabelecia os referencias de qualidade para cursos à distância, constavam os itens básicos para Projetos Político-Pedagógicos de programas que utilizassem dessa metodologia (BRASIL, 2007). Um dos itens dizia respeito à comunicação/interação entre os agentes que compõem esse método educacional.

Para Moran (2007, p. 10), os encontros presenciais podem ou não fazer parte do processo de educação a distância, entretanto, essa acontece de forma fundamental com professores e alunos em espaços e tempos diferentes que ficam juntos através de tecnologias de comunicação.

Nesse contexto, ganha um papel de importante destaque a figura do tutor a distância, que deve ser compreendido como um dos sujeitos que participa ativamente no processo pedagógico (BRASIL, 2007). Assim, a intervenção feita pelo tutor pode influir diretamente na qualidade do processo de ensino aprendizagem. Logo, é importante acompanhar o desempenho dos tutores em sua atuação no processo de aprendizagem, verificando se este está dentro das metas previstas pela instituição e necessárias a um ensino de qualidade.

Entretanto, monitorar a ação dos tutores não é uma tarefa tão simples, uma vez que estes geram um grande número de dados a serem analisados. Assim, é de grande importância a existência de métodos e ferramentas que façam o acompanhamento do desempenho dos tutores à distância em suas atribuições, favorecendo a gerência e coordenação das atividades de tutoria (CAVALCANTE, SOUSA e SOUSA, 2015).

O presente trabalho propõe uma metodologia de avaliação de tutores de caráter qualitativo baseada na metodologia de análise de desempenho feedback $360^{\circ}$. Na proposta, há um foco múltiplo sobre a atividade de tutoria, pois a avaliação é feita por todos os atores que interagem com o tutor: alunos, colegas de trabalho e ele próprio, possibilitando uma análise mais ampla. Desse modo, espera-se que, por meio da aplicação do método, os resultados gerados possam contribuir para a identificação de potencialidades e fragilidades, e, consequentemente, melhorias no apoio, formação e atuação dos tutores. 


\section{1 - O TUTOR EM EAD: CONCEITOS E ATRUBUIÇÕES}

Segundo os Referências de Qualidade de Educação Superior a Distância, para que se tenha um sistema de tutoria de qualidade deve ser prevista a atuação de profissionais tutores presenciais e a distância. Aqueles atendem os alunos nos pólos de apoio e participa de encontros presenciais, ao passo que estes atuam com os alunos geograficamente distantes do pólo, esclarencendo dúvidas e promovendo espaços de construção de aprendizagem, dando suporte para tanto (BRASIL, 2007).

Um bom tutor deve promover a realização de atividades e apoiar a realização destas oferecendo novas fontes de informação e favorecendo sua compreensão e não somente mostrar as respostas corretas (MACHADO e MACHADO, 2004, p. 3). Entretanto, para que os objetivos da tutoria sejam atingidos, é necessário que o tutor possua determinadas competências e habilidades.

Nesse sentido, Borges \& Souza (2012, p. 5) organizaram as competências dos tutores em quatro grupos de acordo com as ações desenvolvidas por esse profissional, a saber: pedagógicas, abrangendo aspectos relacionados ao aprendizado grupal e individual; sócio-afetiva, relacionadas a questões interpessoais, criatividade e socialização; tecnológica, relacionadas a aspectos técnicos e domínio das tecnologias usadas nos AVAs; e auto-avaliativa, envolvendo a percepção do tutor em relação a sua própria atuação, com foco na melhoria do trabalho.

Nessa mesma linha, Aretio (2002 apud TECCHIO ET. AL., 2009) expõe que é necessario que o tutor possua algumas qualidades como autenticidade, maturidade emocional, cordialidade, compreensão de si mesmo, empatia, inteligência e agilidade mental, capacidade de escuta e aceitação, liderança, entre outras. De forma mais descritiva, Tecchio et. al. (2009), elencam as competências dos tutores dividindo-as em comportamentais, as quais abrangem aspectos como pró-atividade, empatia, criatividade, liderança e comprometimento; e técnicas, como conhecimento das disciplinas, AVA e EaD, trabalho em equipe e comunicação oral/escrita.

De acordo com o exposto, é necessário ver o papel da tutoria como sendo mediar as necessidades do aluno e as possibilidades oferecidas pelos curso, atuando de forma comprometida, em busca da aprendizagem autônoma contruída por meio da interação virtual (BORGES e SOUZA, 2012, p. 5).

\subsection{AVALIAÇÃO DE TUTORES}


Conhecer o papel do tutor no contexto do processo de ensino aprendizagem em EaD não é suficiente para garantir o bom êxito dos resultados, faz-se necessário também acompanhar o desempenho em suas atividades no decorrer do curso. O MEC, nos Referências para Cursos de Educação Superior a Distância, prevê, dentre as funções das instituições de ensino, a de avaliar os tutores, bem como outros profissionais que atuam nos polos de apoio com o intuito de garantir padrões de qualidade no suporte aos estudantes (BRASIL, 2007, p. 12).

Nessa perspectiva, Ronchi et. al. (2012, p. 44) realizaram uma pesquisa bibliográfica na qual foram elencadas variáveis a serem consideradas na construção de modelos para avaliação do desempenho da tutoria em EaD, dividindo-as em características pessoais, habilidades técnicas e atribuições a desempenhar. A Figura 1 apresenta as critérios agrupados em cada categoria.

Figura 1 - Critérios de avaliação de tutores (Ronchi et. al., 2012, p. 44).

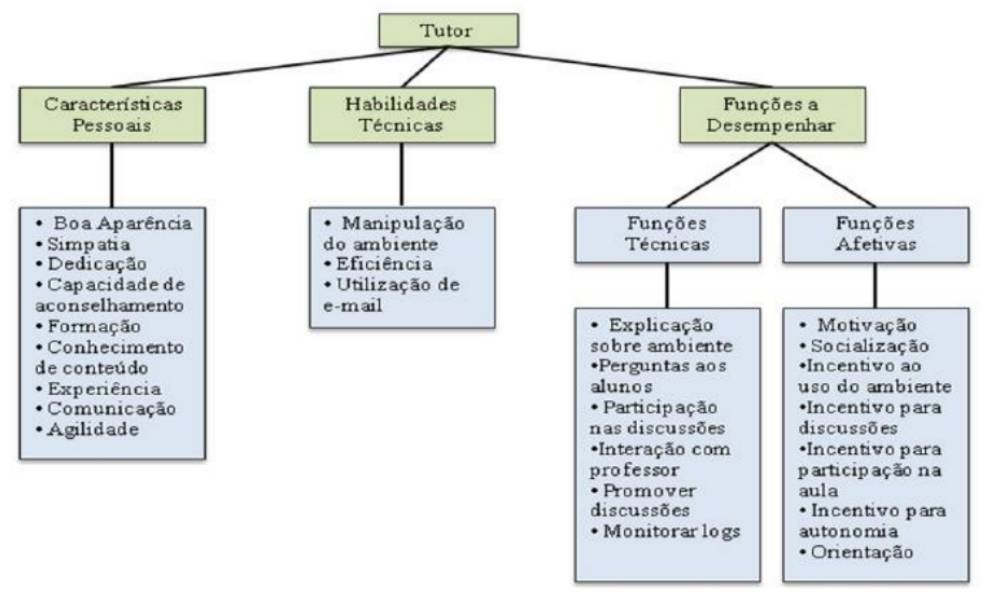

Um estudo de caso feito por Paula et. al. (2008) propõe um modelo de avaliação do desempenho de tutores que consiste na aplicação de um questionário aos alunos versando sobre o apoio do tutor a estes no decorrer dos cursos. Para os autores, a aplicação dessa metodologia de forma sistêmica, possibilita a tomada de decisão e a potencialização de pontos positivos (PAULA ET. AL., 2008).

Spressola (2010) propõe um instrumento de avaliação das competências no trabalho de tutoria $\mathrm{EaD}$, o qual consiste em um questionário a ser aplicado aos alunos, tutores e coordenadores de cursos, baseado nas competências e levando em consideração a periodicidade da ação presente na pergunta. As respostas dos questionários de alunos, tutores e coordenadores são, por sua vez, cruzadas em um esquema de triangulação para identificar eventuais problemas (SPRESSOLA, 2010). 
Em seu estudo, Leitão Cavalcante (2014) define um método e constrói uma ferramenta computacional chamada MDTMoodle que permite acompanhar o desempenho das atribuições dos tutores à distância com base em métricas quantitativas, a qual analisa as atividades do tutor em suas atribuições, gerando um relatório gráfico que facilita a visualização do rendimento pela equipe de supervisão desses profissionais e sua consequente intervenção.

Com base nesses estudos, pode-se perceber o quão complexa é a tarefa de avaliar o desempenho de tutores, dado a grande quantidade de atribuições e dados gerados, a multiplicidade de abordagens possíveis, além do caráter específico da relação do tutor com os vários atores do processo de ensino EaD. Desse modo, é importante haver uma concentração de esforços no sentido de estudar como mensurar o desempenho do tutor e assim desenvolver mecanismos que facilitem essa tarefa, tornando-a mais estruturada, rápida e eficiente, o que impactará positivamente nos objetivos e rendimentos educaionais pretendidos.

\subsection{AVALIAÇÃO DE DESEMPENHO FEEDBACK $360^{\circ}$}

Dentre as várias metodologias de avaliação de desempenho utilizadas pelas organizações, está a metodologia feedback $360^{\circ}$ (trezentos e sessenta graus), também conhecida como avaliação múltipla, avaliação de multivisão ou feedback de múltipla avaliação. Nesse método, a avaliação é feita de modo circular por todos aqueles que mantém alguma interação com o funcionário avaliado (CHIAVENATO, 2014, p. 246). Ou seja, o colaborador é avaliado não só pelo seu chefe, mas por todos aqueles que interagem com ele no desempenho de suas atividades, conferindo-lhe um caráter mais abrangente e dinâmico. Devido essa abordagem feita pelo entorno, essa metodologia torna-se mais rica, pois produz informações diversas vindas de todos os lados e funciona no intuito de assegurar adaptabilidade e ajustamento do funcionário às variadas demandas a ele impostas (CHIAVENATO, 2014, p. 246).

Para Lopes, Vigarani, \& Faria, 2007, para que uma organização utilize o feedback 360 é necessário que sejam seguidos os seguintes critérios: participação de todas as pessoas que interagem com o avaliado; feedbacks devem ser simultâneos e estruturados; utilização de questionários específicos que abordem aspectos relevantes para a organização; avaliação com caráter qualitativo; resultados confidenciais.

Dentre as principais características que configuram a avaliação 360 estão: melhorar os resultados, conhecer o potencial individual frente novos desafios, identificar problemas e necessidades de melhorias, adequação ao trabalho e maior produtividade, melhorar a 
comunicação e relações interpessoais, liberdade total dos avaliadores e criação de um processo de feedback estruturado por quem conhece o trabalho (BISPO, 2003, p. 11).

Esse modelo traz vantagens, como, qualidade dos resultados dada a familiaridade dos avaliadores com o trabalho, sigilo traz mais conforto para o avaliador podendo resultar em dados mais neutros e honestos, maior aceitação por parte dos avaliados, visto que a análise parte de pessoas conhecidas e resultados tendem a ser mais confiáveis e impessoais devido a quantidade de feedbacks(FELIPPE, 2005).

Entretanto, como todo processo avaliativo, a avaliação $360^{\circ}$ não está isenta de desvantagens. Entre os problemas a serem enfrentados estão a possibilidade de haver subjetividade nas respostas ocasionada por emoções e interpretações pessoais; ser um processo mais demorado, pois envolve grande número de pessoas; se os avaliados não tiverem maturidade suficiente, pode haver má aceitação dos resultados; e a elaboração dos questionários pode não ser feita de forma clara e objetiva.

Apesar das desvantagens, a finalidade para as organizações é, em suma, procurar obter informações úteis sobre o desempenho do funcionário, de modo que este conheça seus comportamentos laborais e melhorando a produtividade da organização, orientando cada um a atingir suas metas (LOPES, VIGARANI e FARIA, 2007). Desse modo, esse instrumento de avaliação pode ser de grande utilidade no ambiente organizacional desde que aliado aos objetivos e estratégias da organização.

\section{METODOLOGIA FEEDBACK 360 APLICADA À AVALIAÇÃO DE TUTORES EAD: UMA PROPOSTA DE ABORDAGEM}

Tomando por base o referencial teórico apresentado neste trabalho, é proposta uma aplicação da metodologia de avaliação de desempenho feedback 360 na avaliação de tutores EaD. A proposta consiste em elencar avaliadores, atributos e parâmetros a serem seguidos com a finalidade de aferir a qualidade da atuação do tutor em suas atividades, comparando-a aos objetivos e metas da instituição de ensino ou programa no qual ele está inserido.

Na proposta, o tutor seria avaliado em três dimensões: pedagógica, administrativa e autoavaliativa. Cada dimensão contaria com um questionário construído com base nas atividades de tutoria, objetivos da instituição de ensino e particularidades da relação do tutor com os que se enquadram naquela dimensão.

Na dimensão pedagógica, haveria um foco na avaliação do aluno em relação à atuação 
do tutor. Na dimensão administrativa, o questionário seria respondido pelos colegas de instituição que lidam com o profissional tutor, entre eles o seu supervisor e demais tutores. Já na dimensão autoavaliativa, o tutor seria arguido sobre o seu próprio desempenho, envolvendo questões técnicas, administrativas e pedagógicas, podendo abordar, inclusive, informações sobre o suporte da instituição às suas atividades.

Para cada pergunta, o avaliador teria que escolher em uma escala de 0 (zero) a 5 (cinco) conforme o avaliado se enquadre naquele quesito, onde o 0 representa a impossibilidade de avaliar devido a não existência de dados ou não se aplicar à relação entre eles, 1 o desempenho pior possível e 05 o melhor possível dentro da escala. Essa forma de análise possui um caráter qualitativo, pois não está pautada na quantidade de eventos ocorridos, mas na qualidade do trabalho como um todo.

No intuito de retratar os resultados obtidos nos questionários, é proposta uma equação para cada dimensão, a qual expressa numericamente o desempenho do tutor. No geral, as equações consistem em médias aritméticas entre os resultados de todos os avaliadores. Objetivando não prejudicar o resultado geral por dimensão, é proposto que, para fins de contabilização no cálculo da dimensão, sejam descartadas as respostas dos avaliadores que responderem 0 a mais de $50 \%$ das questões. Desse modo, busca-se evitar a influência de avaliações incompletas no resultado.

Como baseia-se na ferramenta feedback $360^{\circ}$, a metodologia ora proposta tem um caráter cíclico. O processo de aplicação inicia-se com a adequação dos questionários à instituição de ensino e termina com as intervenções detectadas como necessárias através da interpretação dos resultados. A Figura 2 traz o ciclo de implantação proposto.

Figura 2 - Ciclo de funcionamento da metodologia de avaliação.

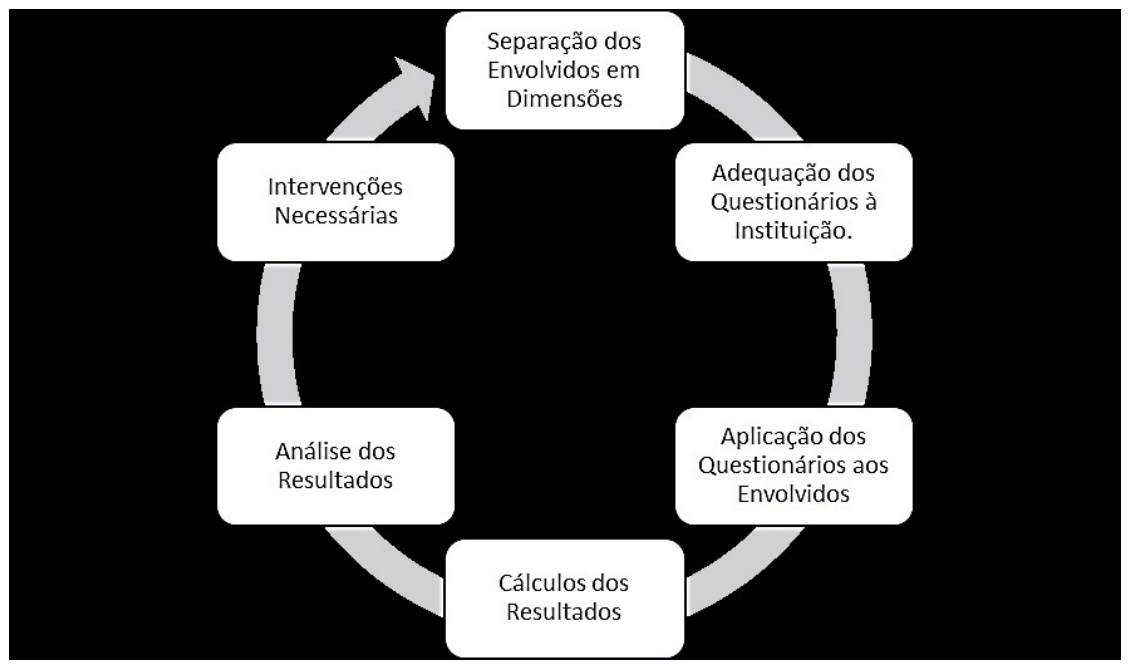


No intuito de fornecer também uma visão geral sobre o desempenho do tutor baseado nas três dimensões, é proposto um cálculo baseado nos resultados obtidos, o qual segue a forma da média aritmética ponderada, no intuito de distribuir os pesos conforme a importância da dimensão no contexto considerado, tornando possível uma adaptação às necessidades da instituição. Assim, na equação original a dimensão auto avaliativa pode receber um peso menor que as demais, com o intuiro de reduzir a influência de possível subjetividade a que essa dimensão está sujeita.

O modelo ora proposto possui a característica de poder adaptar-se ás necessidades da instituição, pois possibilita adequações referentes à alteração do número e natureza das questões, pesos dados a cada dimensão, podendo inclusive ser inseridas novas dimensões, caso seja necessário. O caráter lógico matemático dessa metodologia dá abertura para o desenvolvimento de ferramentas que integrem a avaliação no AVAs e possibilitem a mecanização dos cálculos, bem como a divulgação dos resultados gerais para os envolvidos na avaliação.

\section{CONCLUSÃO}

Nesse trabalho, foi proposta uma metodologia de caráter qualitativo de avaliação de desempenho de tutores em EaD baseada na ferramenta de avaliação feedback $360^{\circ} \mathrm{e}$ na bibliografia que trata sobre a temática, a qual envolve todos os atores que interagem com o tutor no cotidiano de seu trabalho em cursos a distância, considerando competências, habilidades e atividades inerentes à tutoria.

Através da aplicação dessa melodia nas instituições que fornecem a modalidade de educação à distância, espera-se facilitar o trabalho de monitoramento da qualidade dos serviços prestados pelos tutores, identificado fragilidades, problemas e potencialidades através dos indicadores gerados pela metodologia.

Como trabalhos futuros relacionados a essa pesquisa, sugere-se o teste do modelo em ambiente real, afim de verificar sua efetividade e fazer as adequações necessárias. Além disso, é proposto o desenvolvimento de uma ferramenta computacional que automatize os cálculos inerentes à metodologia e se integre a AVAs.

São necessárias pesquisas que abordem a temática da análise da atuação do tutor no cenário $\mathrm{EaD}$, desenvolvendo novas formas de proceder e testando modelos e ferramentas existentes, aprimorando, assim, sua aplicabilidade e pertinência. Desse modo, haverá uma evolução dos métodos e consequentemente o melhoramento no processo educativo a distância, gerando ganhos para as instituições de ensino, para os 
alunos, para os tutores e, consequentemente, da sociedade como um todo, que terá disponibilizada para si uma educação de maior qualidade, com os benefícios intrínsecos à modalidade EaD.

\section{REFERÊNCIAS}

ARETIO, L. G. La educaión a distancia: de la teoría a la práctica. Barcelona: Ariel, 2002.

BISPO, P. Avaliação 360 Graus - um caminho para melhorar o desempenho, 22 set. 2003. Disponivel em: . Acesso em: 14 jun. 2016.

BORGES, F. V. A.; SOUZA, E. R. D. Competências Essenciais ao Trabalho Tutorial: estudo bibliográfico. Simpósio Internacional de Educação a Distância - SIED. São Carlos: [s.n.]. 2012.

BRASIL. Referências de Qualidade para Educação a Distância. Ministério da Educação. Brasília. 2007.

CAVALCANTE, C. H. L.; SOUSA, V. L. P. D.; SOUSA, P. B. M. D. Acompanhamento do Desempenho das Atribuições de Tutores a Distância: Método e Ferramenta. EaD em Foco: Revista Científica em Educação a Distância, Rio de Janeiro, v. 5, n. 1, p. 1-11, 2015. Disponivel em: . Acesso em: 12 jun. 2016.

CHIAVENATO, I. Gestão de Pessoas: o novo papel dos recursos humanos nas organizações. 4. ed. Rio de Janeiro: Elsevier, 2014.

FELIPPE, M. I. Avaliação de desempenho, 28 mar. 2005. Disponivel em: . Acesso em: 11 jun. 2016.

LEITÃO CAVALCANTE, C. H. Uma abordagem de Acompanhamento das Atribuições de Tutores a Distància, Fortaleza, p. 105, 2014. Disponivel em . Acesso em: 15 Junho 2016.

LOPES, C. R. G.; VIGARANI, M. P.; FARIA, G. S. S. AVALIAÇÃO DE DESEMPENHO 360: UM CONFRONTO ENTRE. Nucleus, v. 4, p. 131-140, 2007. Disponivel em: . Acesso em: 14 jun. 2016. 
2004. Disponivel em: . Acesso em: 06 Junho 2016.

MEDEIROS, L. E. A. Sistema de Tutoria em Cursos a Distância. Texto base para o Curso de Implementação e Gestão da Educação a Distância. Módulo 5. Rio de Janeiro: Universidade Federal Fluminense, 2007.

MORAN, J. M. O Que é Educação a Distância, 2007. Disponivel em: . Acesso em: 08 jun. 2016.

PAULA, A. D.; CASTANHEIRA, N. P.; SELEME, R. Educação a distância: proposta para avaliaçao do desempenho do tutor na educação a distância., Maio 2008. Disponivel em: . Acesso em: 09 jun. 2016.

RONCHI, S. H. E. A. Avaliação de Desempenho da Tutoria de Educação a Distância: um estudo da produção científica internacional para identificação das variáveis a comporem um modelo de avaliação. Revista Eletrônica Perspectivas Contemporâneas, Campo Mourão, v. 7, p. 27-52, Julho/Dezembro 2012. ISSN 2.

SPRESSOLA, N. A. Instrumento para Avaliar as Competências no Trabalho de Tutoria na Modalidade EaD. Universidade de São Paulo. São Carlos. 2010.

TECCHIO, E. L. et al. Competências Fundamentais ao Tutor de Ensino a Distância. Colabor@ - Revista Digital da CVA, v. 6, Outubro 2009. ISSN 21. Disponivel em: . Acesso em: 10 Junho 2016. 